\title{
EL PATRIMONIO ARTISTICO ESPAÑOL DURANTE LA GUERRA CIVIL (1936-1939) EL CASO DEL PORTAPAZ DE UCLÉS
}

\section{THE SPANISH ARTISTIC HERITAGE DURING THE CIVIL WAR (1936-1939) THE CASE OF THE UCLÉS PORTAPAZ}

\author{
Ángel Mora Urda \\ (Doctor en Arqueología y Patrimonio, España) \\ moraurda6@gmail.com
}

Recibido: 19 febrero 2020 Aceptado: 07 marzo 2020

\begin{abstract}
Resumen: La Guerra Civil española (1936-1939) supuso una seria amenaza para el patrimonio del país. En este sentido, varias fueron las acciones llevadas a cabo, principalmente a nivel gubernamental, para salvaguardar los bienes (tanto mueble cómo inmueble) culturales y artísticos. Esta cuestión ha sido ampliamente abordada en los últimos años desde varias perspectivas de estudio que nos permiten acercarnos al conocimiento de estas acciones de protección patrimonial. En este artículo se pone sobre la mesa la historia de la desaparición y recuperación, en parte, del Portapaz del Monasterio de Uclés, una pieza de orfebrería única encargada por la Orden de Santiago y que albergaba una placa bizantina del siglo XI.
\end{abstract}

Palabras clave: Guerra Civil; Patrimonio artístico; Monasterio de Uclés; Portapaz; Anástasis

\footnotetext{
Abstract: The Spanish Civil War (1936-1939) posed a severe threat to this country's heritage. In this respect, on a governmental level, several actions were undertaken in order to safeguard movable property and cultural and artistic immovable property. Over the last years, this issue has been widely addressed from various study perspectives, that allow us to grasp a better knowledge on these actions regarding heritage protection. This article puts the spotlight on the disappearing and partial recovery of the Monastery of Uclés pax, an unique silversmithing piece commissioned by the Order of Santiago. This piece holded a byzantine plaque from the 11th century.
} 
Keywords: Civil War; Artistic heritage; Monastery of Uclés; pax; Anastasis

\section{INTRODUCCIÓN}

La Guerra Civil española (1936-1939) y la dictadura franquista (1939-1975) son los dos acontecimientos históricos que han marcado la trayectoria de España durante el siglo XX llegando hasta nuestros días. Tras el conflicto bélico y durante la dictadura surgió un nuevo orden político, social y cultural que en gran medida rompía con la tradición anterior. En este sentido, el patrimonio artístico español no estuvo ajeno a los acontecimientos. Su salvaguarda y protección fue un tema capital en plena Guerra Civil. Así ha quedado atestiguado en los últimos años por las numerosas aportaciones sobre el estudio del patrimonio durante la guerra (Alted Vigil, 1984; Álvarez Lopera, 1982; Argerich Fernández; Cabañas Bravo, 2007; 2008; Colorado Castellary; Pérez Sánchez; Martínez Ripoll, 1991; Colorado Castellary, 2008a, 2008b, 2010, 2014a, 2014b; EstebanChapapría, 2007; Gracia Alonso; Munilla, 2011; Monreal Tejada, 1999; Muñoz Rubio, 2010; Renau, 1980; Saavedra Arias, 2011; 2012; Tusell, 1986; 1999). Sin embargo, la posguerra es un periodo menos abordado en esta materia. En la actualidad, se están llevando a cabo investigaciones en este sentido como la realizada por el proyecto "Investigación histórica y representación digital accesible. El patrimonio artístico durante la guerra y la posguerra" (http://pgp.ccinf.es/PGP/\#/proyecto) quienes están llevando a cabo una investigación de catalogación y estudio de miles de obras de arte salvadas durante la guerra por la República, así como un seguimiento de estas durante la posguerra.

El presente artículo pretende hacer hincapié en el Portapaz de Uclés. Se trata de una pieza de indudable valor histórico y artístico, del S. XVI, perteneciente al Monasterio de Uclés (Cuenca) y cuya serie de acontecimientos desde la Guerra Civil y la posguerra, con desaparición incluida de la pieza, ha llegado casi hasta nuestros días.

\section{CUERPO DEL TEXTO}

La Guerra Civil española (1936-1939) y su contexto supusieron un auténtico cataclismo que afectó a todos los ámbitos y espacios. Así, el conflicto y sus consecuencias repercutieron en la sociedad, la demografía, la economía, la política, la educación, la 
industria, etc. Todas estas cuestiones han sido, en mayor o menor medida, ampliamente abordadas y estudiadas por los historiadores durante todos estos años, especialmente tras la muerte del dictador Francisco Franco (1975). El Patrimonio Histórico y Artístico español también se vio involucrado y afectado sobremanera por la guerra y sus consecuencias.

En este sentido, la protección del rico Patrimonio Histórico-Artístico español fue una cuestión capital para el gobierno republicano. Su salvaguarda se puso sobre la mesa especialmente a raíz de la comprobación de los daños sufridos por los edificios tras los bombardeos y el desmantelamiento de edificios civiles o religiosos para albergar tropas, refugiados, civiles o almacenes, según necesidades derivadas de la contienda. Para garantizar la protección del patrimonio español el 23 de julio de 1936 se creó la Junta de Incautación y Protección del Tesoro Artístico, dependiente de la Dirección General de Bellas Artes y, por ende, del Ministerio de Instrucción Pública. La principal función de esta Junta era la de intervenir "con amplias facultades cuantos objetos de arte o históricos y científicos se encuentren en los palacios ocupados, adoptando aquellas medidas que considere necesarias para su mejor conservación e instalación" (Almarcha, 2000, p.280). Con anterioridad, en Madrid ya se habían realizado algunos esfuerzos notables para salvaguardar el Patrimonio de la capital. La Dirección General de Bellas Artes era consciente plenamente del reto al que se enfrentaba debido a los bombardeos sufridos por Madrid. Contamos con testimonios directos del esfuerzo de la capital por proteger sus Bienes como el de Vázquez Camarasa, el canónigo que entró en el Alcázar de Toledo para auxiliar religiosa y espiritualmente a los encerrados, quien declaró en la Causa General que en Madrid "las iglesias estaban precintadas y respetadas" (Causa General, Anexo X en, De la Vega, 2007, p.127). También en la Generalitat de Cataluña se tomaron medidas, especialmente tras la quema de algunas iglesias. Estas medidas de protección estaban encaminadas principalmente a la salvaguarda de la Catedral de Barcelona y Pedralbes. Además de esto, el 27 de julio (un día después de la creación de la Junta Central) el Gobierno de la Generalitat incautó por decreto diferentes colecciones artísticas y se aseguró el rescate de otras muchas colecciones que habían caído ya en poder de organizaciones sindicales o personas individuales. 
Serán varios los factores, derivados principalmente del transcurso de la guerra, los que expliquen el traslado y la destrucción de muchas obras artísticas, factores que esencialmente se pueden sintetizar en dos: en primer lugar, las ofensivas militares y los bombardeos de las ciudades y, en segundo lugar, la situación en la retaguardia de refugiados, heridos y la recluta de soldados. Para esta segunda cuestión era necesario instalar cocinas, almacenes, albergues u hospitales, como es el caso que nos ocupa del Monasterio de Uclés. Antes de continuar analizando en profundidad esta cuestión, es importante discernir el futuro uso dado al inmueble incautado (iglesia, monasterio, palacio, etc.) ya que esto nos va a ayudar a discriminar entre destrucción o desmantelamiento. En muchos casos estos conceptos se confunden dependiendo de la fuente consultada, no siendo lo mismo, ya que la mayoría de estos edificios ocupados fueron desmantelados para salvaguardar las obras artísticas, sirva de ejemplo los numerosos casos de desmonte de los retablos de las iglesias. Madrid es uno de los ejemplos más validos a la hora de analizar la salvaguarda de obras y edificios artísticos, ya que la situación de la capital durante toda la guerra fue dramática: asediada y bombardeada indiscriminadamente. Llena de palacios, museos y bibliotecas, la capital de la República se convirtió en un gran campo de acción para todos estos necesarios y arriesgados trabajos de protección y salvamento del patrimonio histórico-artístico (De la Vega, 2007, p.147).

La situación del Patrimonio Artístico de la provincia de Cuenca no fue muy diferente al resto de las provincias de la España republicana, aunque sí que van a destacar las actuaciones de la Junta Delegada del Tesoro Artístico de Cuenca. Dicho órgano fue creado el 24 de abril de 1937 y presidido por el consejero provincial de Cultura, Antonio Dorrego Seoane y los vocales Juan Giménez Cano, Alfredo Malo Zarco, Cándido Pérez Gasión, Miguel Kreisler Padín, José López Toro, Francisco del Valle Pérez y Eliseo González Mateo (Almarcha, 2000, p.282). Derivado del carácter de provincia de retaguardia, en Cuenca serán numerosos los ejemplos de inmuebles que vieron alterados sus usos rutinarios para pasar a albergar otra funcionalidad completamente distinta en virtud de las necesidades derivadas de la contienda. Edificios como iglesias, monasterios, la catedral conquense, o palacios como el episcopal de la capital, se vieron desmantelados para albergar hospitales, cocinas, cuarteles o almacenes. Podemos destacar el caso de la 
Catedral de Cuenca, cuyo tesoro fue incautado por la CNT en los primeros momentos de la guerra, lo que dio lugar a un largo litigio entre el Gobierno y la Junta Central del Tesoro Artístico, por un lado, y la organización sindical por otro. Finalmente, los elementos patrimoniales fueron devueltos en junio de 1937, pasando a ser custodiado en Valencia junto con los fondos del Museo del Prado y muchos otros Bienes del resto de España allí trasladados (Almarcha, 2000, p.281).

En cuanto al resto de la provincia, esta sí que se vio sometida a incursiones y movimientos de tropas que, como en el caso de la célebre Columna del Rosal, venían de combatir en Madrid, Guadalajara o Alcalá. Tradicionalmente se ha relacionado estos trasiegos de milicianos con posibles destrozos o incautaciones de Bienes muebles, especialmente en edificios eclesiásticos. Para el análisis de este tema es esencial la consulta de la obra de Víctor de la Vega (De la Vega, 2006) quién ha realizado un completo estudio acerca del patrimonio artístico conquense durante la Guerra Civil. A nivel provincial De la Vega se basa principalmente en el Catálogo Monumental de la Diócesis de Cuenca, publicado por la Diputación Provincial en 1987 y, en segundo lugar, la obra de Sebastián Cirac (Cirac, 1947). En la custodia y recogida de objetos entre las pequeñas localidades conquenses tuvo, desde el primer momento, un papel protagonista y de especial relevancia, Juan Giménez Aguilar, quien, desde su cargo de Delegado Provincial de Bellas Artes, impuso una tutela gubernamental frente a posibles incautaciones y destrucciones de Patrimonio (Almarcha, 2000, p.288).

Sin entrar en más detalles ni casuísticas, llegados a este punto cabe centrase en el objeto de esta investigación. Para profundizar más en las cuestiones anteriormente perfiladas, se remite al lector interesado a la bibliografía citada.

Por su importancia como edificio monumental y de sobradas proporciones que favorecen casi cualquier uso, así como su ubicación geográfica dominando visualmente la comarca y en un nudo de comunicaciones, el Monasterio de Uclés siempre formó parte del escenario de la guerra. Y no solamente nos referimos a la cronología que nos ocupa, ya que este edifico jugó un papel relevante en el último tercio del siglo XIX durante la Tercera Guerra Carlista y, especialmente, durante la invasión francesa y la conocida como Guerra de Independencia (1808 - 1814) ya que se instaló en el Monasterio un cuartel 
general que sirvió de base para las tropas del comandante Francisco Xavier Venegas que entraron en combate contra las tropas francesas del Mariscal Víctor el 13 de enero de 1809 en la célebre Batalla de Uclés (Vela Santiago, 2015).

De nuevo dentro del contexto de la Guerra Civil, el monasterio fue convertido en hospital militar y por una decisión personal de Antonio María Sbert, Conseller de Cultura de la Generalitat, una parte de los fondos bibliográficos del monasterio fueron trasladados a la Biblioteca de Cataluña. El resto de los fondos, así como la estructura y arte mueble del monasterio parece ser que fueron respetados tanto por el personal médico como por los militares. En su obra, Sebastián Cirac nos dice que "la iglesia parroquial y la del monasterio fueron asaltadas y destrozadas totalmente, habiendo desaparecido cuanto en ellas había" (Cirac, 1947, p.531). Sin embargo, dicha afirmación queda desmentida ya que el estado de la iglesia parroquial era deplorable en 1931 como atestigua Juan Giménez de Aguilar: "El pueblo debía lamentar todavía más que de su antigua parroquia de Santa María apenas sí quedan señales...” (De la Vega, 2007, p.196).

Uno de los elementos artísticos más destacados del monasterio y objeto principal de este estudio, es el del Portapaz de Uclés, cuya serie de acontecimientos ha llegado casi hasta nuestros días. [1]

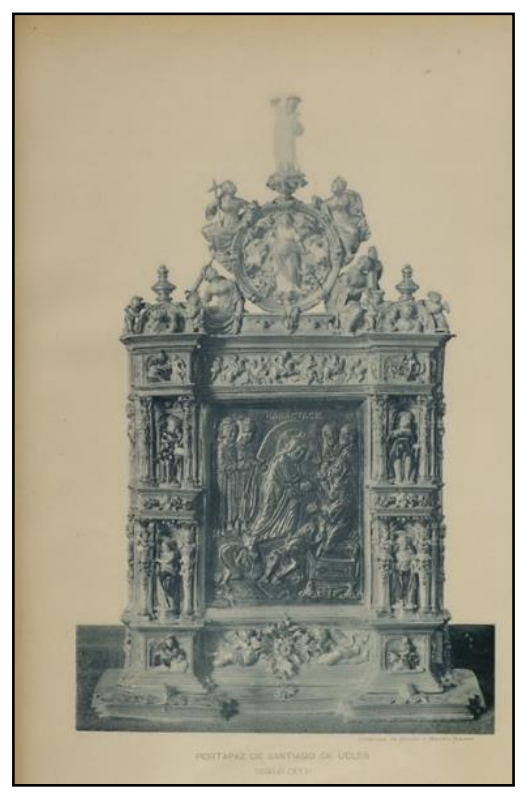

1. Fototipia de Hauser y Menet (Madrid) del Portapaz de Uclés, (Sociedad Española de Excursiones 1896: 18) 
El Portapaz de Uclés, uno de los tres que se conservan en el mundo (junto a uno en Estambul y al de Roma) servía de pieza ritual en las ceremonias católicas para simbolizar la paz. Los caballeros de la Orden de Santiago, que regentaban en el siglo XVI el Monasterio de Uclés, encargaron a Francisco Becerril, uno de los mejores artistas españoles de la época, el pequeño retablo para colocar una placa bizantina del siglo XI y que representaba una Anástasis de clara procedencia o, al menos, influencia oriental. El tema de la Anástasis está probado por una inscripción en la parte superior: HANACTACIC [2]

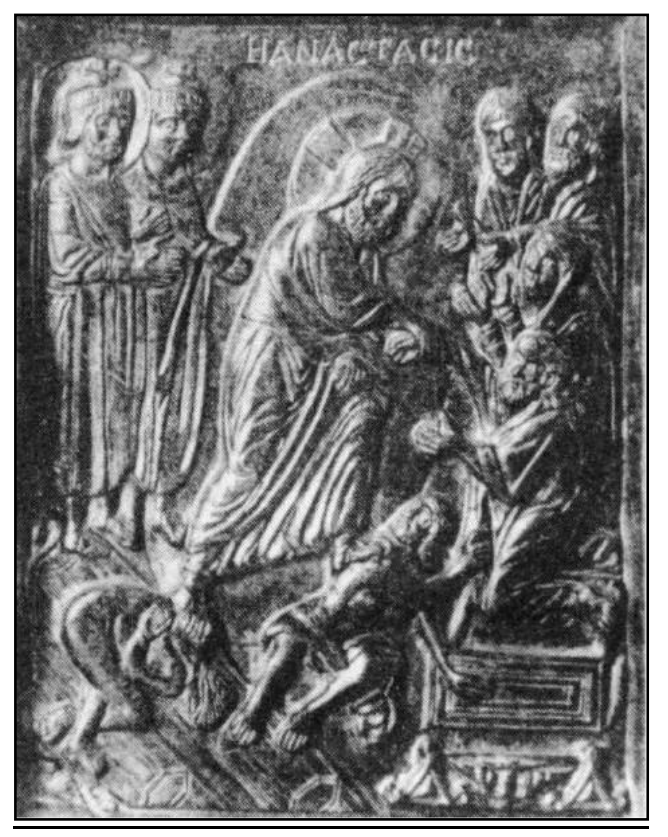

2. Detalle de la placa central del Portapaz de Uclés donde se puede apreciar la inscripción HANACTACIC en la parte superior

La Anástasis es la transliteración del vocablo griego utilizada para la resurrección de Cristo. Dentro del contexto religioso, la Anástasis se refiere al descenso de Jesucristo al Limbo de los Patriarcas, lugar donde residieron las almas de los justos con anterioridad a la redención de la cruz siendo rescatados por Jesús resucitado. Este episodio es ampliamente descrito en el evangelio Apócrifo de Nicodemo y en Nuevo Testamento (Mt. 27:52-53) aunque de manera más sucinta. En Arquitectura, este concepto es utilizado para referirse a la zona de una iglesia dedicada a la resurrección de Cristo, dándose especialmente en iglesias bizantinas, destacando el Santo Sepulcro de Jerusalén. Por lo tanto, la Anástasis ha sido un tema muy utilizado y recurrente dentro de la iconografía bizantina, especialmente en el periodo ortodoxo post-iconoclasta. 
Volviendo al Portapaz de Uclés, Francisco Becerril realizó una verdadera joya de orfebrería, labrada en oro y plata y acompañada de esmaltes. (Alcolea, 1958, p.188). El boletín de la Sociedad Española de Excursiones publicaba en su III tomo (marzo 1895febrero 1896) en sus páginas 19-20, un artículo sobre el Portapaz de Uclés, escrito por Enrique de Leguina. El texto va acompañado de una fototipia de Hauser y Menet de Madrid. Se trata de una magnifica descripción de la pieza (Sociedad Española de Excursiones, 1896, pp.19-20):

“Ocupa el centro un bajo relieve labrado en serpentina, que tiene por asunto la resurrección de Lázaro. Por la colocación de las figuras, el plegado de los paños y la tosquedad de la ejecución revela el carácter romano-bizantino del último periodo, y, por consiguiente, fecha muy anterior a la del trabajo de orfebrería que le sirve de marco.

Los regulares y correctos cuerpos arquitectónicos que componen esta pieza son notabilísimos, y presentan toda le elegancia y fausto del estilo plateresco, que tantas maravillosas obras produjo en nuestra patria.

Columnas en forma de cariátides; delicadas estatuitas de San Pedro, San Pablo, Santiago y San Juan Bautista, en las hornacinas de ambos lados; pequeñas y finas imágenes de los cuatro Evangelistas, colocadas en los netos de las bases y frisos de la cornisa; diminutas figuras representando la batalla de Clavijo, ocupando todo el friso superior; el medallón del coronamiento con la imagen de la Inmaculada Concepción, rodeada de ángeles: las Virtudes cardinales que completan el decorativo conjunto y la esmaltada estatua del Salvador, que terminan la obra, son todas armónicas partes de un armonioso conjunto que demuestra la pericia del autor de tan prodigiosa y perfecta joya.

No es menos notable, ni en nada desmerece, por cierto, de este bellísimo todo, el asa, que representa una quimera alada; hecha tan gallarda y briosamente como pudo soñar la creadora fantasía del artista, reverso de la alhaja, por sí solo suficiente para hacerla digna de la admiración de los inteligentes. 
El carácter perfectamente definido del Renacimiento español que, inspirándose en las suntuosidades de Pavía creó el estilo llamado plateresco; el hallarse dedicado el porta-paz al convento de Uclés, y llevar las emblemáticas insignias de la Orden, las tradicionales conchas, la imagen de Santiago y el recuerdo de Clavijo, bastarían para que no pudiera dudarse de que esta obra, que compite con los más acabados productos del arte de la orfebrería, es de procedencia nacional: más por fortuna no se necesita, acudir para asegurarlo a presunciones más o menos fundadas, pues una de las marcas que conserva, revela haber sido construido en Cuenca, por tener sus blasones y la palabra Cuen..

Otros tres punzones se hallan en el porta-paz, pero hasta ahora no se han descifrado. Tal vez sea alguno de ellos del famoso Cristóbal Becerril, que en aquella ciudad labró el precioso osculatorio que se guarda en El Escorial, y la custodia de Alarcón, ó de alguno de sus hermanos, que con aquél hicieron la de la catedral de Cuenca, y que por cierto tiene por coronamiento, como el portapaz de que nos ocupamos, una pequeña estatua del Salvador".

Junto con la descripción expuesta, el mejor estudio acerca del Portapaz de Uclés, en cuanto a su temática y elementos artísticos, es el realizado por Milagros Guardia, (1986). A modo de conclusión acerca de este estudio centrado en la obra que nos ocupa, todo parece indicar que sigue un modelo iconográfico creado en Oriente y definido por la posición de Jesucristo, el cual se mueve hacia la derecha al lugar donde se encuentra Adán portando una mandorla en su mano (Guardia, 1986, p.111). Junto a esto destaca también la ausencia de la cruz, el hecho de que Hades aparezca sin atar y la presencia de las puertas del infierno, pero sin haber sido cruzadas. El estudio y comparativa de estos elementos arroja una cronología en torno al siglo XI para la pieza central del Portapaz de Uclés (Guardia, 1986, pp.86-111).

Tras la desamortización de Mendizábal, y al calor de la creación del obispadopriorato de las órdenes militares en 1876, el Portapaz de Uclés fue trasladado desde el Monasterio de Uclés hasta la catedral de Ciudad Real. Esta será la ubicación permanente de la pieza hasta el año 1937. Con los acontecimientos de la Guerra Civil, el Gobierno Civil decide, junto a muchas otras piezas, su incautación y posterior traslado a Valencia. 
Será en este momento cuando, el que fuera director general de la Caja de Reparaciones del Ministerio de Hacienda de la República, Amaro del Rosal, encuentra unas pequeñas piezas dentro de unas cajas. Pero Del Rosal no sospechó entonces que esas piezas pertenecieran al Portapaz, a pesar de que tenía conocimiento de su desaparición. Como las investigaciones para esclarecer su origen no dieron fruto positivo, el responsable de la Caja de Reparaciones decidió custodiarlas. Con su exilio, Amaro del Rosal las llevó consigo hasta su regreso a España en 1977. Será entonces, cuando se ponga en contacto con el historiador del arte Fernando Martín y a raíz también de la investigación de Francisco Alía Miranda cuando se logren identificar las piezas, que fueron devueltas a la Diócesis de Ciudad Real en 1986 (49 años después de su desaparición) para ser expuestas en la Catedral. Varios medios informativos se hicieron eco de la noticia, tanto de la desaparición (Sánchez, 19/09/1978) como de la posterior reaparición (Castro, 20/10/1986), dando una visibilidad acorde al valor de la pieza. Las figuras recuperadas representan imágenes de los apóstoles San Pedro, San Juan, San Pablo y Santiago, además de un medallón que ilustra la Asunción de María y otra figura del Salvador que remata el Portapaz. Del resto de figuras, así como de la placa bizantina central no se tienen constancia de su paradero, siendo la opción más probable su venta y dispersión durante los 80 años pasados desde su desaparición. [Fig. 3] 


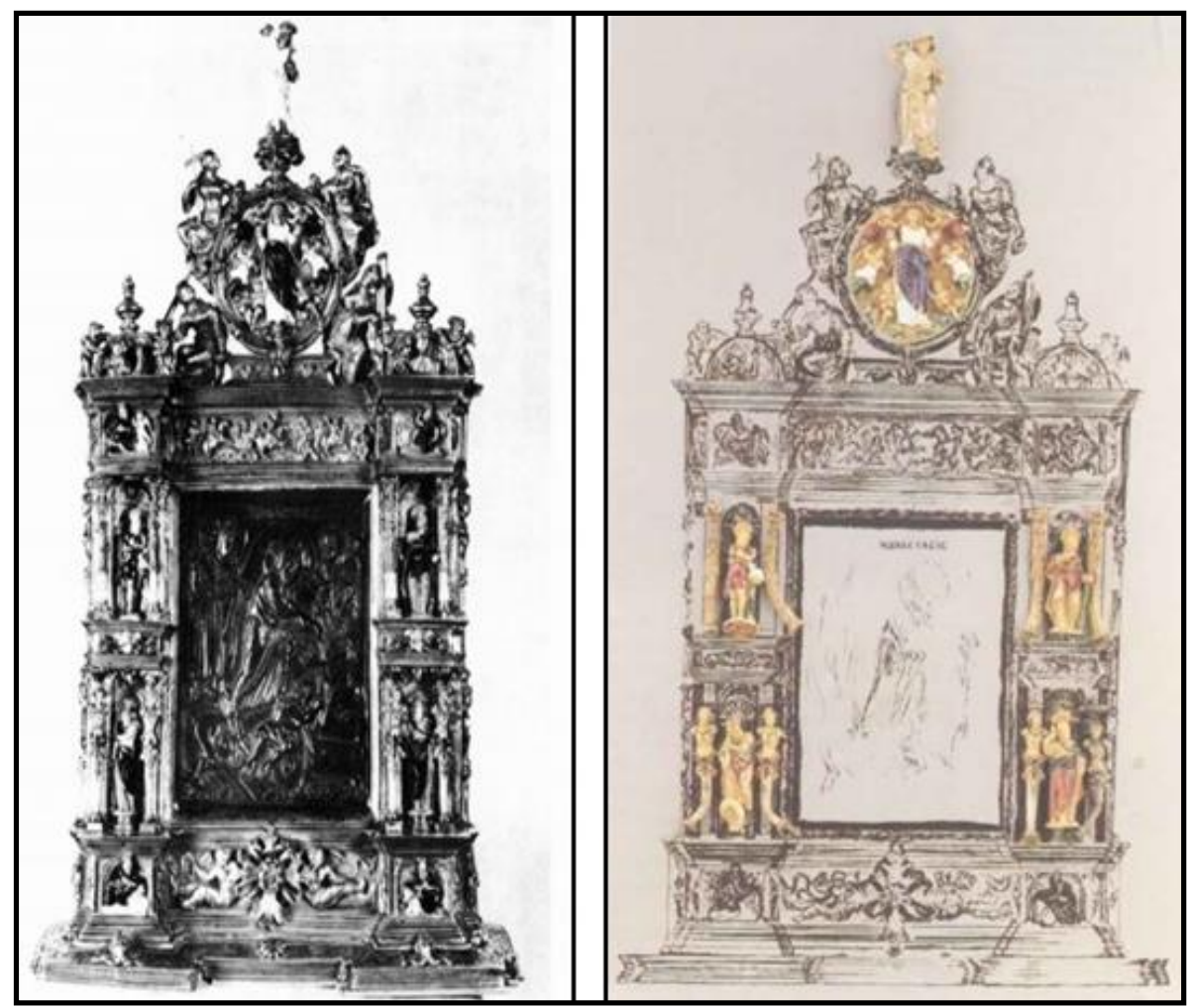

3. A la izquierda, fotografía del Portapaz de Uclés (Guardia, 1986: 91). A la derecha, composición con los restos recuperados de la pieza (http://www.ciudad-real.es/historia/ccm/siglo20-06.php)

\section{CONCLUSIONES}

A lo largo de su historia, España ha ido acumulando un rico Patrimonio HistóricoArtístico de bienes, tanto inmuebles como muebles, cuya protección y salvaguarda debe estar siempre presente. La cruenta Guerra Civil y posguerra a la que el país tuvo que hacer frente durante el siglo XX puso a prueba la capacidad de la sociedad y, especialmente, de las autoridades en materia de protección del patrimonio español. Una de las características de este conflicto bélico fue la introducción por primera vez de los bombardeos masivos sobre las ciudades. Esta circunstancia hizo necesario establecer una serie de actuaciones para evitar la destrucción de elementos como museos, iglesias, esculturas, etc.

En el contexto del asedio al que fue sometida la ciudad de Madrid desde finales de octubre de 1936 y atendiendo a razones logísticas derivadas de la falta de edificios lo suficientemente habilitados como para asegurar que las obras de arte no sufrirían los efectos de los bombardeos a los que estaba siendo sometida la capital, el Gobierno presidido por Largo Caballero tomó la trascendental decisión de evacuar una selección 
de las principales obras de arte custodiadas a Valencia, a donde también se trasladaba la sede del Gobierno. Esta decisión mediatizó toda la política de salvaguarda republicana puesto que, lejos de ser una medida aislada, se convirtió en su principal estrategia para asegurar la conservación del patrimonio. Esta política de evacuación del patrimonio fue la que afectó al Portapaz de Uclés, llevándolo hasta la ciudad del Turia.

La política de control directo ejercida por los Gobiernos republicanos sobre el patrimonio, aunque, al final de la guerra supuso la conservación de las piezas, no estuvo exenta de problemas derivados de algunos envíos arriesgados que produjeron innumerables contratiempos.

Por su parte, las autoridades sublevadas se habían mostrado más lentas e ineficaces que las gubernamentales a la hora de desarrollar instrumentos y normativas para proteger y conservar el patrimonio histórico-artístico que había en su retaguardia. No fue hasta diciembre de 1936, seis meses después del inicio del conflicto, cuando se produjeron las primeras disposiciones en este sentido. Fue entonces cuando se crearon una serie de organismos, primero, las Juntas de Cultura Histórica y del Tesoro Artístico y, poco después, para complementarlas, los Servicios Artísticos de Vanguardia. El principal objetivo de este organismo era localizar las obras de arte que había antes de la guerra en las zonas de retaguardia bajo su control y, en caso de encontrarse en peligro de pérdida o deterioro, recuperarlas y ponerlas bajo su custodia. Sin embargo, la falta de personal y de medios económicos mermaron su capacidad de acción.

En la actualidad contamos con un buen número de estudios acerca de las medidas llevadas a cabo para salvaguardar el patrimonio durante la Guerra Civil e incluso los primeros años de la posguerra. Dichas investigaciones están poniendo de relieve el buen hacer de las autoridades gubernamentales que lograron un gran porcentaje de éxito custodiando y amparando estos elementos patrimoniales.

Sin embargo, también contamos con testimonios que nos narran la desafortunada destrucción o desaparición de Bienes muebles o inmuebles de incalculable valor Histórico-Artístico. Uno de estos casos es el del Portapaz de Uclés. Se trata de una obra única de orfebrería encargada por la Orden de Santiago a Francisco Becerril y la cual 
incluía una placa bizantina del siglo XI que representa una Anástasis. Esta obra, conservada en la catedral de Ciudad Real, fue trasladada a Valencia en 1937. Con su salida forzosa al exilio, Amaro del Rosal (director general de la Caja de Reparaciones del Ministerio de Hacienda de la República) se llevó una caja con algunas piezas. Tras su vuelta a España en 1977 entregó dichas piezas, las cuales pertenecían al Portapaz de Uclés. Sin embargo, la pieza central, la obra bizantina del siglo XI, nunca ha llegado a aparecer siendo un ejemplo más de patrimonio desaparecido en un contexto bélico.

En último lugar, las iniciativas y proyectos de investigación que se han llevado a cabo en los últimos años en nuestro país están arrojando luz acerca la salvaguarda del Patrimonio en el contexto bélico. Estos proyectos, como los citados anteriormente, nos traen de vuelta iniciativas, políticas de salvaguarda y, en ocasiones, piezas artísticas recuperadas. Sin embargo, aún queda trabajo por realizar y un ejemplo de esto es el caso aquí expuesto del Portapaz de Uclés, pieza de la cual aún no se ha logrado una recuperación y restitución total de sus elementos.

\section{REFERENCIAS BIBLIOGRÁFICAS}

Alcolea, Santiago (1958). Artes decorativas en la España Cristiana (siglos XI-XIXI). Ars Hispaniae: Madrid.

Almarca Núñez-Herrador, Esther. (2000). “Arte, Patrimonio artístico y Guerra Civil en Castilla - La Mancha", en, ORTIZ, M. La Guerra Civil en Castilla-La Mancha. De El Alcázar a Los Llanos. Celeste Ediciones: Madrid.

Alted Vigil, Alicia. (1948). Política del nuevo Estado sobre el patrimonio cultural y la educación durante la Guerra civil española. Ministerio de Cultura: Madrid.

Álvarez Lopera, José. (1982). La política de bienes culturales del Gobierno republicano durante la Guerra civil española. Ministerio de Cultura: Madrid.

Arguerich Fernández, Isabel. \& Ara Lázaro, Judith. (eds.). (2003). Memoria de la Junta del Tesoro Artístico durante la Guerra Civil. Museo Nacional del Prado: Madrid.

Cabañas Bravo, Miguel. (2007). Josep Rena, arte y propaganda en guerra. Ministerio de Cultura: Madrid. 
- (2008). “Josep Renau, director general de Bellas Artes” en Cabañas Bravo, M., López Yarto, A. y Rincón García, W. Arte, poder y sociedad en la España de los siglos XV a XX. CSIC: Madrid, pp. 369-387.

Castro, Eva. (20/10/1986). Un funcionario de la Republica entrega una valiosa colección de orfebrería, el portapaz de Uclés había desaparecido en 1937. El País. Recuperado de: https://elpais.com/diario/1986/10/20/cultura/530146808_850215.html

Cirac Estopañán, S. (1947). Martirologio de Cuenca. Crónica diocesiana de la época roja. Barcelona.

Colorado Castellary, Arturo. (2008a). Éxodo y exilio del arte. La odisea del Museo del Prado durante la Guerra Civil. Cátedra: Madrid.

- (2008b). "La salvaguarda del patrimonio artístico nacional en Valencia", en Aznar Soler, M., Barona, J. y Navarro, J. (eds.), València, capital cultural de la República (1936-1937), PUV-SEC: Valencia. pp. 409-432.

- (2010). "El Acuerdo de Figueras y el salvamento del patrimonio artístico español", en Canal, J. (dir). Figueras, capital de la República: 1 de febrero de 1939. Congreso de los Diputados: Madrid. pp. 107-128.

- (2014a). 'L'Accord de Figueras: son contexte, le Comité International et sa mise en oevre", en NÉGRI, V. Le patrimoine culturel, cible des conflits armés. De la guerre civile espagnole aux guerres du 2le siècle, Bruylant: Bruxelles. pp. 21-62.

- (2014b). "la premessa spagnola: evacuazione, intervento internazionale e salvataggio del patrimonio artístico durante la Guerra civile”, en Calvano, T. y Forti, M. Musei e monumento in guerra 1939-45. Londra-Parigi-Roma-Berlino. Edizioni Musei Vaticani: Città del Vaticano.pp. 2755.

Colorado Castellary, Arturo, Pérez Sánchez, Emilio. \& Martínez Ripoll, Antonio. (1991). El Museo del Prado y la Guerra civil (Figueras-Ginebra, 1939). Museo del Prado: Madrid.

De la Vega Almagro, Víctor. (2007). Tesoro artístico y Guerra Civil. El caso de Cuenca. Ediciones de la Universidad de Castilla - La Mancha: Cuenca. 
Esteban Chapapría, Juñián. (2007). La conservación del patrimonio español durante la II República 81931-1939). Fundación Caja de Arquitectos: Barcelona.

García Alonso, Francisco. y Munilla, Glòria. (2011). Salvem l'art. La protección del patrimoni cultural català durant la Guerra civil. La Magrana: Barcelona.

Guardia, Milagros. (1986). Una obra bizantina de Ciudad Real y el tema de la Anástasis. En D'Art: Revista del Departament d'Historia de l'Arte, n'.12, pp. 86-112.

Monreal Tejada, Luis. (1999). Arte y Guerra civil. La val de Onsera: Huesca.

Muñoz Rubio, María. (2010). La historia recuperada. Vicisitudes del palacio de Liria durante la Guerra civil, en Junta de Andalucía (ed.). Colección Casa de Alba. Museo de Bellas Artes: Sevilla, pp. 103-109.

Renau, Jean. (1980). Arte en peligro, 1936-1939. Fernando Torres - Ayuntamiento de Valencia: Valencia.

Saavedra Arias, Rebeca. (2011). La sorte del patrimonio artístico spagnolo durante la Guerra civile (1936-1939): ideología, politicae trascendenza del problema. En Diacronie. Studi di storia contemporánea, $\mathrm{n}^{\circ} 7$ Spagna anno zero: la guerra come soluzione.

Saavedra Arias, Rebeca. (2012). "La destrucción del patrimonio artístico durante la Guerra Civil. El caso cántabro", en Aramburu Zabala, M., Losada Varea, Celestina. \& Saavedra Arias, Rebeca. (2012). Patrimonio destruido en Cantabria, PUbliCan, Ed. de la Universidad de Cantabria: Santander, pp. 49-105.

Sánchez Lillo, Jorge. (19/09/1978). El desaparecido portapaz: una maravillosa obra de orfebrería del tesoro catedralicio de Ciudad Real. En Lanza Dominical (19/09/1978).

Sociedad española de Excursiones. (1986). Boletín de la Sociedad Española de Excursiones. Tomo III, marzo 1895- febrero 1896. Madrid.

Tusell, Javier. (1986). La cultura, botín de guerra. En Lápiz, revista internacional de arte, v. $36, n^{\circ} 4$, pp. 29-32.

Tussel, Javier. (1999). Arte, historia y política en España (1890-1939). Biblioteca Nueva: Madrid.

Vela Santiago, Francisco. (2015). El desastre de Uclés. 1809. Alamena Ediciones: Madrid. 
Dipòsit digital de documents de la UAB (1893-1954). Boletín de la sociedad española de excursiones en le repositorio de la Universidad Autónoma de Barcelona.

Recuperado de: https://ddd.uab.cat/record/40577/?ln=es

Investigación histórica y representación digital accesible (2015-2017). El patrimonio artístico durante la guerra y la posguerra. Recuperado de:

http://pgp.ccinf.es/PGP/\#/proyecto

Turismo y Cultura en Ciudad Real. Tierra del Quijote 2003-2020, 17 años en la red (2003-2020). Ciudad Real del siglo XX. La Guerra civil. Recuperado de:

http://www.ciudad-real.es/historia/ccm/siglo20-06.php 